\title{
Management of Pediatric Chronic Spontaneous Urticaria: A Review of Current Evidence and Guidelines
}

This article was published in the following Dove Press journal: Journal of Asthma and Allergy

\author{
Jasmine Chang $\mathbb{D}^{\prime}$ \\ Leila Cattelan ${ }^{2}$ \\ Moshe Ben-Shoshan (iD ${ }^{3}$ \\ Michelle Le ${ }^{2}$ \\ Elena Netchiporouk (iD) ${ }^{2}$ \\ 'Department of Medicine, McGill \\ University, Montreal, Quebec, Canada; \\ ${ }^{2}$ Division of Dermatology, McGill \\ University Health Centre, Montreal, \\ Quebec, Canada; ${ }^{3}$ Division of Allergy \\ Immunology and Dermatology, Montreal \\ Children's Hospital, Montreal, Quebec, \\ Canada
}

\begin{abstract}
Chronic urticaria (CU) is associated with debilitating symptoms such as pruritic wheals and/or angioedema, which can significantly affect patients' sleep, productivity and quality of life. Chronic spontaneous urticaria (CSU) is defined in cases in which no triggering factor is identified. Various guidelines directing the optimal management of $\mathrm{CU}$ in the adult population were published and updated over the recent years with the most accepted and widely used being the EAACI/GA²LEN/EDF/WAO 2017 guidelines. Meanwhile, guidelines specific to the pediatric population are scarce, mainly due to the fact that high quality evidence is lacking for many treatment options in this age group. The objective of this article is to review and synthesize the existing literature regarding the management of pediatric CSU. Our review highlights evidence supporting the EAACI/GA²LEN/EDF/WAO 2017 treatment guidelines with non-sedating second-generation antihistamines (sgAHs) as the mainstay of treatment for pediatric CSU, considering their demonstrated efficacy and reassuring safety profile. Additionally, the use of omalizumab in adolescents is well supported by the current literature. There is limited data available regarding the updosing of sgAHs, omalizumab in children with CSU under 12 years of age and the treatment with cyclosporine and leukotriene receptor antagonists (LTRAs) in pediatric patients of all ages. However, the results from currently available case series and case reports are promising for omalizumab and cyclosporine use in children with CSU, although large and well-designed randomized control trials (RCTs) assessing these treatment options are needed in order to formulate strong recommendations for their use. First-generation antihistamines (fgAHs) remain commonly used in pediatric CSU treatment despite a lack of studies assessing their efficacy and safety in the pediatric population and their widely known inferior safety profile compared to sgAHs.
\end{abstract}

Keywords: chronic spontaneous urticaria; CSU, chronic urticaria; CU, treatment, management, guidelines, children, pediatric

\section{Introduction}

Chronic urticaria (CU) is defined as presence of pruritic wheals, angioedema or both occurring on most days of the week and persisting for at least 6 weeks. ${ }^{1}$ Recent evidence suggests that $\mathrm{CU}$ in children may be as frequent as in adults with point prevalence estimates of $0.5 \%-1.5 \%$ affecting males and females equally. ${ }^{2-6}$ Approximately $20 \%$ of $\mathrm{CU}$ cases have a proven physical/inducible trigger and are known as chronic inducible urticaria (CIndU), ${ }^{6}$ while in the remaining cases, hives occur spontaneously and are known as chronic spontaneous urticaria (CSU) (historically referred to as chronic idiopathic urticaria). ${ }^{7}$
Correspondence: Elena Netchiporouk Division of Dermatology, McGill University, 1650 Cedar Ave, Montreal, Quebec, H3G IA4, Canada Email elena.netchiporouk@mail.mcgill.ca
Journal of Asthma and Allergy 202I:14 187-199 
The clinical manifestations of pruritus, hives and angioedema are direct consequences of mast cell degranulation and release of preformed or newly synthetized inflammatory/ vasoactive mediators (e.g., histamine, platelet-activating factor, cytokines) and neuropeptides. ${ }^{1,2}$ While the exact etiopathogenesis of CSU is not yet clearly defined, ${ }^{8,9}$ the most widely accepted hypothesis is that mast cells are activated through autoimmune mechanisms, such as the binding of immunoglobulin (Ig)G antibodies directed against IgE or its high affinity receptor (FceRI). ${ }^{10-14}$ Furthermore, adult CSU literature demonstrated that in the majority of cases, various IgE-type autoantibodies against self-proteins, such as interleukin (IL)-24 or thyroid peroxidase, may directly bind and crosslink the FceRI, although this has not yet been demonstrated in children. ${ }^{12,15-17}$ This mechanism is referred to as auto-allergic and can possibly co-exist with IgG-mediated CSU (Figure 1). ${ }^{12,15-18}$ More recently, IgM and IgA autoantibodies against FceRI have as well been identified in adult patients with CSU. ${ }^{19}$ Autoimmunity in CSU can be demonstrated in vivo, through autologous serum skin test (ASST), or in vitro, through basophil histamine release assay (BHRA), basophil activation test (BAT) or by the presence of autoantibodies against IgE or FceRI on immunoassays. ${ }^{1,20,21}$ ASST is not routinely performed due to practical challenges and in vitro tests, such as BAT, are not recommended for routine use as their clinical utility remains to be confirmed and so far, their results do not impact patients' management. ${ }^{1,20,21}$

Various guidelines directing the optimal management of CSU in the adult population were published and updated over the recent years. ${ }^{1,20,21}$ The most accepted and widely used are the EAACI/GA ${ }^{2} \mathrm{LEN} / \mathrm{EDF} / \mathrm{WAO}$ guidelines which are endorsed by many international societies and were last updated in 2017. ${ }^{1}$ While these guidelines include children as a special population, they unfortunately remain underutilized in clinical practice. ${ }^{9}$ The objective of this article is to review and synthesize the existing literature regarding the management of pediatric CSU.

\section{Treatment Objectives}

The actual strategy of CSU management is focused on complete or near-complete symptom control until the

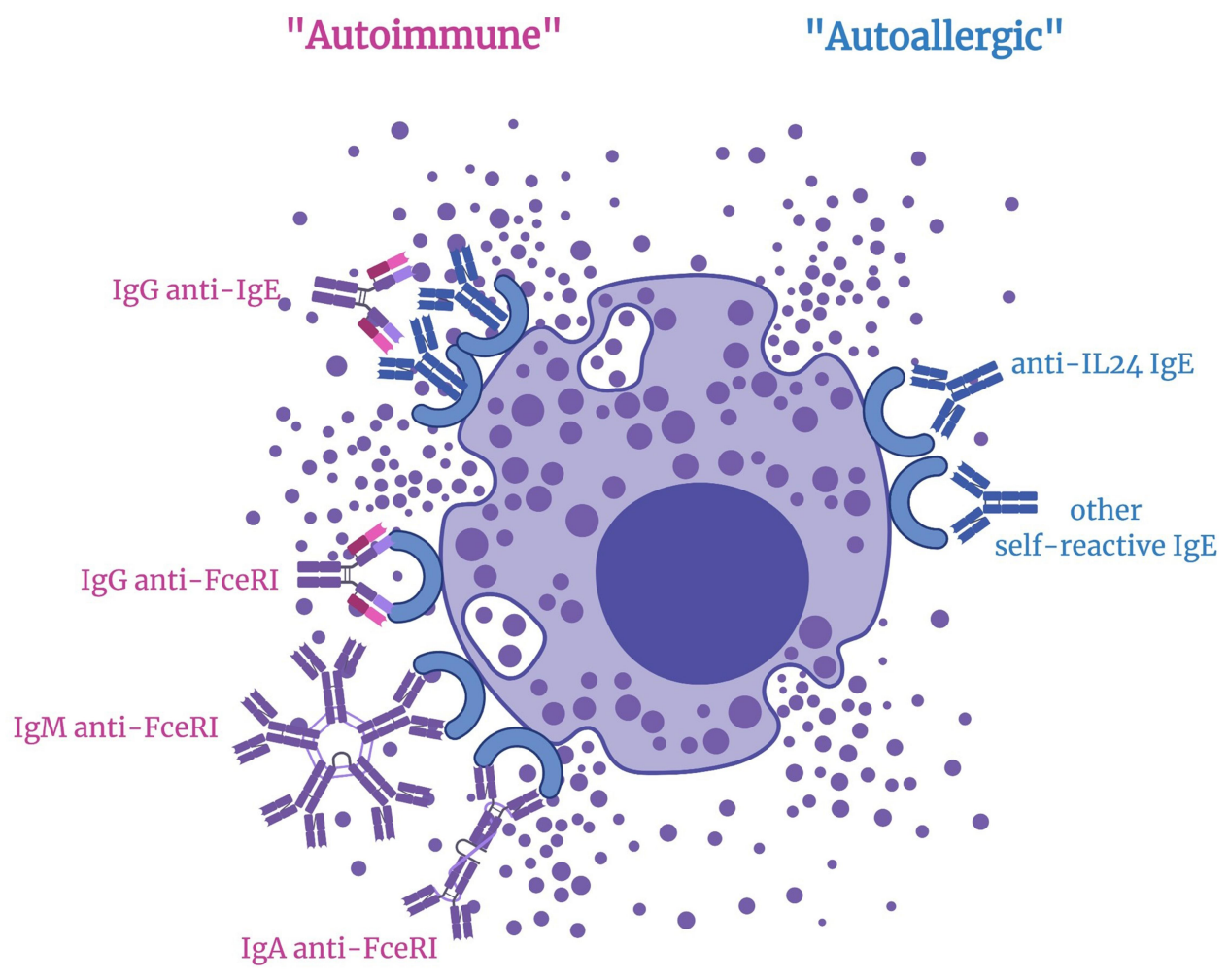

Figure I Pathogenesis of chronic spontaneous urticaria (CSU) - current concepts.

Notes: The most accepted hypothesis is that mast cell degranulation is triggered by lgG antibodies against the lgE molecule or its high affinity receptor, FceRI in $\sim 50 \%$ of cases. In additional cases, mast cell activation and degranulation may occur due to functionally active lgE-type autoantibodies (e.g., anti-IL-24 IgE, anti-TPO IgE). IgM and IgA autoantibodies against FceRI have as well recently been identified in adult patients with CSU. Created with BioRender $B$.

Abbreviations: FceRI, high affinity IgE receptor; IgE, Immunoglobulin E; IgG, immunoglobulin G; IgM, immunoglobulin M; IgA, immunoglobulin A; IL-24, interleukin-24; TPO, thyroid peroxidase. 
disease resolves spontaneously, with optimization of number of drugs and dosage needed to achieve control and maintain it. Disease severity and treatment responses can be assessed quickly and effectively using widely available tools such as the weekly Urticaria Activity Score (UAS-7) and the Urticaria Control Test (UCT). ${ }^{22,23}$ A UAS-7 score $\leq 6$ is defined as well-controlled disease, UAS-7 score between 7 and 15 as mild disease, while severe disease is associated with UAS-7 scores $\geq 28 .^{24}$ A UCT score $\geq 12$ corresponds to a satisfactory disease control, while a score $\leq 11$ is associated with poorly-controlled disease. ${ }^{23}$

CSU has a substantial individual and societal impact due to debilitating symptoms such as severe pruritus and secondary loss of sleep and productivity. ${ }^{25,26}$ Higher prevalence of mood and anxiety spectrum disorders have been shown in pediatric CSU patients as opposed to controls. $^{26,27}$ Children with CSU were found to have severe impairment in their health-related quality of life, similar to other chronic diseases such as epilepsy and diabetes, ${ }^{25}$ and a significantly lower school performance compared to those with other allergic diseases. ${ }^{26}$ Pediatric CSU is a chronic disease that may last up to 10 years and we have recently demonstrated that CSU resolution rate in children is similar to adults, at 10 per 100 -patient-years. ${ }^{6}$ Hence, there is a necessity for effective and safe symptom management over many years for children with CSU. While the disease has been suggested to resolve faster in children with autoimmune forms and basopenia, ${ }^{6}$ no treatment to date has been proven to alter the natural history of this disease.

\section{CSU Treatment Guidelines}

The 2017 EAACI/GA ${ }^{2} \mathrm{LEN} / \mathrm{EDF} / \mathrm{WAO}$ international guidelines recommend using the same treatment algorithm for CSU in pediatric patients as in adult patients, although it is recommended to use it with caution since many of the drugs included have not yet been adequately studied in children (Figure 2). ${ }^{1}$ As a first step for management, the guidelines recommend avoiding identifiable triggers (e.g., non-steroidal anti-inflammatory agents) and physical stimuli, which are particularly relevant in cases of comorbid CSU/CIndU. In terms of pharmacological treatment, a stepwise algorithm is recommended starting with nonsedating second-generation $\mathrm{H} 1$-antihistamines (sgAHs) at standard dosage as first-line therapy. If symptom control is insufficient, subsequent step-up in therapy with increasing dosage of sgAHs up to fourfold the licensed dose is recommended and may result in up to $90 \%$ of children having well-controlled symptoms. ${ }^{28}$ In cases of antihistamine (AH)-resistant CSU, the guidelines recommend adding omalizumab (a monoclonal anti-IgE antibody) to the sgAH therapy. However, the use of omalizumab is currently approved by Health Canada, the Food and Drug Administration (FDA) and other jurisdictions (e.g., United Kingdom, Europe) for children with CSU $\geq 12$ years of age only, and for children with moderate to severe allergic asthma $\geq 6$ years of age. ${ }^{29,30}$ Finally, if symptoms remain inadequately controlled, cyclosporine as an add-on to $\mathrm{sgAH}$ therapy is proposed as a potential fourth step. The international guidelines strongly discourage firstgeneration $\mathrm{H} 1$-antihistamines (fgAHs) use due to their poor selectivity for the $\mathrm{H} 1$ receptor and their ability to cross the blood-brain barrier. fgAHs are associated with pronounced anticholinergic effects and sedative actions on the central nervous system in patients of all ages and especially in children. ${ }^{31-35}$ Additionally, studies assessing commonly used fgAHs for treatment of pediatric CSU, such as diphenhydramine or hydroxyzine, are limited and yet, these treatment regimens remain commonly employed on the basis of their historical extensive use and extrapolation from adult studies. ${ }^{1,9}$ Other therapeutic modalities, which were not included in the stepwise treatment algorithm, but were listed as alternative treatments that may be useful on a case to case basis include: montelukast (a leukotriene receptor antagonist [LTRA]), ranitidine (an $\mathrm{H} 2$-antihistamine [H2-AH]), doxepin (a tricyclic antidepressant with potent antihistamine effects) and more. ${ }^{1}$

The SIP/SIAIP/SIDerP Italian guidelines are the first and only guidelines which delineate treatment recommendations specific to the pediatric population (Figure 2). The Italian guidelines have concordant recommendations for first-line therapy with sgAHs at standard doses. However, their recommendations differ subsequently given the fact that the efficacy and safety profiles of omalizumab and cyclosporine have not been widely studied in patients with CSU under 12 years of age. ${ }^{1,20}$ Conversely, there are several sgAHs approved for pediatric use, including but not limited to the following: cetirizine, loratadine, fexofenadine, levocetirizine, desloratadine, rupatadine and bilastine (age recommendations differ among sgAHs, see Table 1). 1,20,29 The Italian guidelines, similar to the international guidelines, do not recommend use of fgAHs due to their poor side effect profile. The 2 guidelines recommend use of systemic glucocorticoids for short-term treatment only in cases of acute exacerbations of CSU, due to 


\section{THE EAACI/GA2LEN/EDF/WAO 2017 GUIDELINES}

Step 1

Second-generation antihistamines at standard dosage

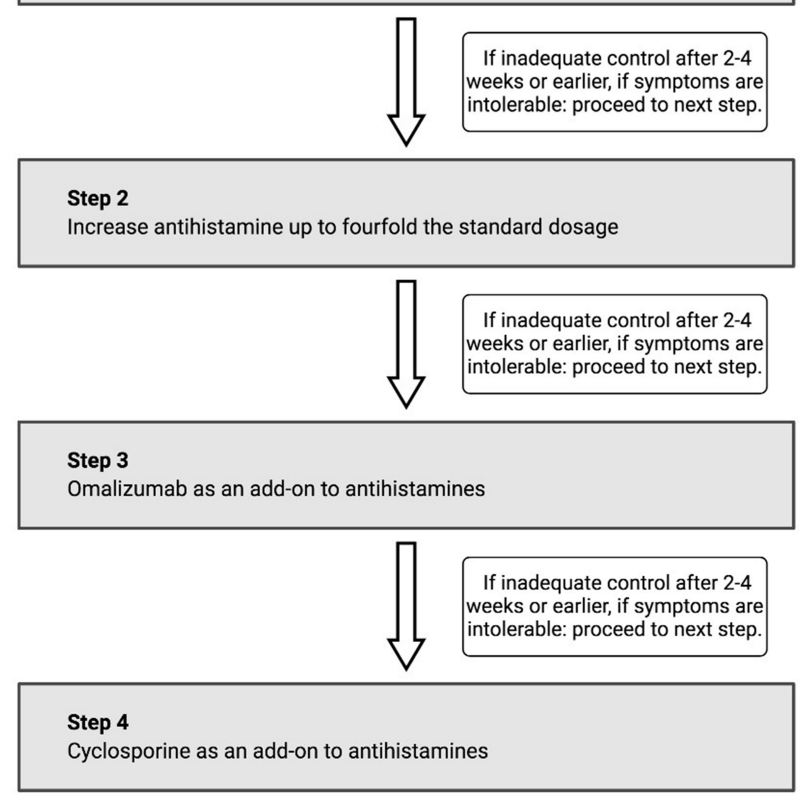

THE SIP/SAIP/SIDerP 2019 GUIDELINES

Step 1

Second-generation antihistamines at standard dosage

If inadequate control after 2-4

weeks or earlier, if symptoms are

intolerable: proceed to next step.

Figure 2 Pediatric CSU treatment guidelines.

Notes: EAACI/GA2LEN/EDF/WAO recommend following the same treatment algorithm in children as in adults, however cautiously given insufficient high-quality data to support omalizumab in children younger than 12 years-old and cyclosporine in pediatric population of all ages. SIP/SAIP/SIDerP guidelines were specifically designed for the pediatric CSU population. Their recommendations mainly differ for patients resistant to labeled dose of sgAHs, recommending updosing of sgAHs up to fourfold in children younger than 12 years of age vs. adding omalizumab to the standard dose sgAH therapy for children older than I2-years-old.

Abbreviation: CSU, chronic spontaneous urticaria.

the high risk of adverse events (AE) with long-term use. $^{1,20,21}$

The AAAAI/ACAAI American guidelines were last updated in 2014, just as omalizumab use had been FDAapproved in adolescent and adult CSU patients and before an important proportion of the literature on omalizumab use in pediatric CSU was published. The American guidelines did not include any specific recommendations for the pediatric population. The AAAAI endorsed for the most part the EAACI/GA ${ }^{2} \mathrm{LEN} / \mathrm{EDF} / \mathrm{WAO}$ treatment recommendations for CSU, although in a recent response paper, the AAAAI maintained their weak recommendation for the trial and use of multiple sgAHs at the same time, H2-AHs, as well as LTRAs given their relative safety and low cost. ${ }^{36}$

\section{Methods}

This narrative literature review included studies that examined management of CSU in pediatric patients published in the last 20 years (January 2000 to April 2020). The review was conducted using the PubMed and EMBASE databases and using the following search terms: ("chronic urticaria"
OR "chronic idiopathic urticaria" OR "chronic spontaneous urticaria”) AND (“infant” OR “child” OR “adolescent” OR "pediatric" OR “childhood") AND ("treatment" OR "management" OR "therapy"). Individual therapies (e.g., fgAHs, sgAHs, omalizumab) were also searched. References of identified manuscripts were manually curated to identify additional articles. Only articles published in the English or French languages were considered. Inclusion criteria comprised studies reporting on the treatment of CSU in humans regardless of the study design. Articles not discussing CSU management, studies which did not include pediatric patients and review articles were excluded.

\section{Discussion}

Articles focusing on the treatment of CSU in pediatric patients were identified for H1-AHs, omalizumab, cyclosporine, zafirlukast, vitamin D supplementation, glucocorticoids, hydroxychloroquine and phototherapy. No articles focusing on pediatric CSU were found for other treatments such as methotrexate, dapsone, doxepin, H2-AHs, rituximab, pseudoallergen-free diet, intravenous immunoglobulin, plasmapheresis, 
Table I Commonly Used Second-Generation Antihistamines in Pediatric Patients

\begin{tabular}{|c|c|c|c|c|}
\hline $\begin{array}{l}\text { 2nd } \\
\text { Generation } \\
\text { Antihistamine }\end{array}$ & Standard Dosage for Age & Contraindications & $\begin{array}{l}\text { Most } \\
\text { Common } \\
\text { Side } \\
\text { Effects }\end{array}$ & Notes \\
\hline Loratadine & $\begin{array}{l}-\geq 2 \text { to }<6 \text { years: } 5 \mathrm{mg} \text { daily } \\
-\geq 6 \text { years: } 10 \mathrm{mg} \text { daily }\end{array}$ & Hypersensitivity & $\begin{array}{l}\text { Headache, } \\
\text { low sedative } \\
\text { potential }\end{array}$ & $\begin{array}{l}\text { Safest during the last trimester of } \\
\text { pregnancy. Not metabolized by the } \\
\text { CYP3A4. }\end{array}$ \\
\hline Desloratadine & $\begin{array}{l}\text { - } 6 \text { to } \leq \text { I I months: I mg daily } \\
\text { - I to } \leq 5 \text { years: } 1.25 \mathrm{mg} \text { daily } \\
\text { - } 6 \text { to } \leq \text { I I years: } 2.5 \mathrm{mg} \text { daily } \\
\text { - } \geq 12 \text { years: } 5 \mathrm{mg} \text { daily }\end{array}$ & Hypersensitivity & $\begin{array}{l}\text { Headache, } \\
\text { diarrhea, } \\
\text { low sedative } \\
\text { potential. }\end{array}$ & $\begin{array}{l}5 x \text { more potent than loratadine in } \\
\text { suppressing wheals. } \\
\text { Safest in patient with renal failure. }\end{array}$ \\
\hline Cetirizine & $\begin{array}{l}\text { - } 6 \text { to }<12 \text { months: } 2.5 \mathrm{mg} \\
\text { daily } \\
\text { - } 1 \text { to }<2 \text { years: } 2.5 \mathrm{mg} \text { once } \\
\text { daily } \\
\text { - } 2 \text { to } 5 \text { years: } 2.5-5 \mathrm{mg} \text { daily } \\
\text { - } 6 \text { to } 11 \text { years: } 5-10 \mathrm{mg} \text { daily } \\
\text { - } \geq 12 \text { years: } 10 \mathrm{mg} \text { daily }\end{array}$ & Hypersensitivity & $\begin{array}{l}\text { Drowsiness, } \\
\text { headache }\end{array}$ & $\begin{array}{l}\text { Can be used during the last } \\
\text { trimester of pregnancy. }\end{array}$ \\
\hline Levocetirizine & $\begin{array}{l}-26 \text { months to } \leq 5 \text { years: } \\
\text { I.25 mg daily } \\
\text { - } 6 \text { to II years: } 2.5 \mathrm{mg} \text { daily } \\
\text { - } \geq 12 \text { years: } 5 \mathrm{mg} \text { daily }\end{array}$ & $\begin{array}{l}\text { Hypersensitivity, end-stage renal } \\
\text { disease, hemodialysis, patients } \leq \mathrm{I} I \\
\text { years with renal impairment }\end{array}$ & $\begin{array}{l}\text { Diarrhea, } \\
\text { drowsiness }\end{array}$ & \\
\hline Fexofenadine & $\begin{array}{l}\text { - } \geq 6 \text { months to }<2 \text { years: } \\
15 \mathrm{mg} \text { twice daily } \\
\text { - } \geq 2 \text { to }<12 \text { years: } 30 \mathrm{mg} \\
\text { twice daily } \\
-\geq 12 \text { years: } 60 \mathrm{mg} \text { twice } \\
\text { daily }\end{array}$ & Hypersensitivity & $\begin{array}{l}\text { Headache, } \\
\text { vomiting, } \\
\text { low sedative } \\
\text { potential. }\end{array}$ & $\begin{array}{l}\text { Safest in patient with renal failure. } \\
\text { Not metabolized by liver/the } \\
\text { CYP3A4. Does not require dose } \\
\text { adjustment in mild renal/ liver } \\
\text { dysfunction. }\end{array}$ \\
\hline Rupatadine & $\begin{array}{l}-\geq 2 \text { to }<12 \text { years: }-10 \mathrm{~kg} \text { to } \\
25 \mathrm{~kg}: 2.5 \mathrm{mg} \text { daily* } \\
\text { - } \geq 25 \mathrm{~kg}: 5 \mathrm{mg} \text { daily } \\
\text { - } \geq 12 \text { years: } 10 \mathrm{mg} \text { daily }\end{array}$ & $\begin{array}{l}\text { Hypersensitivity, history of QTc } \\
\text { prolongation and/or torsades de } \\
\text { pointes, concurrent use of CYP3A4 } \\
\text { inhibitors or other QTc-prolonging } \\
\text { drugs }\end{array}$ & $\begin{array}{l}\text { Drowsiness/ } \\
\text { low sedative } \\
\text { potential, } \\
\text { headache }\end{array}$ & \\
\hline Bilastine & - $\geq 12$ years: $20 \mathrm{mg}$ daily & $\begin{array}{l}\text { Hypersensitivity, history of QT } \\
\text { prolongation and/or torsades de } \\
\text { pointes }\end{array}$ & $\begin{array}{l}\text { Drowsiness/ } \\
\text { low sedative } \\
\text { potential, } \\
\text { headache }\end{array}$ & \\
\hline
\end{tabular}

Note: *While rupatadine tablets are not licensed for children <12-years-old, the use of the oral solution is suggested as per the product monograph.

Abbreviation: CYP, cytochrome-P450.

tranexamic acid, warfarin, mycophenolate mofetil, heparin, colchicine, anti-TNF alpha, tacrolimus and autologous blood or serum.

\section{$\mathrm{HI}$-Antihistamines ( $\mathrm{HI}-\mathrm{AH})$}

H1-AHs bind to the H1 receptor and prevent receptor activation by histamine. ${ }^{33}$ They are the cornerstone for relief of allergic and other hyperhistaminic conditions, such as CSU.
AHs are classified as older fgAHs (e.g., including chlorpheniramine, hydroxyzine, diphenhydramine and doxepin) and more recent sgAHs (see Table 1). Because of their inherent capability to cross the blood-brain barrier and their poor selectivity for the $\mathrm{H} 1$ receptor, fgAHs are associated with significant adverse effects (e.g., sedation, reduced ability to perform skilled tasks/ concentrate at work or school). ${ }^{31-35,37}$ Associated anticholinergic side effects are dose-dependent and several reports of acute 
poisoning and death are published in children. ${ }^{38,39} \mathrm{sgAHs}$ have numerous advantages over their sedating counterparts, notably their selective effect on peripheral $\mathrm{H} 1$ receptors (i.e., less/no central nervous system depression), their longer half-life and their even longer cutaneous half-life. ${ }^{39-43}$

\section{$\mathrm{HI}$-Antihistamines at Licensed Dosage}

Only 1 study compared the efficacy and safety of an sgAH (cetirizine $5 \mathrm{mg}$ daily) to an fgAH (oxatomide $25 \mathrm{mg}$ daily) in children aged 2 to 6 years. ${ }^{44}$ Children treated with cetirizine achieved better control of their itch by day $14(\mathrm{p}<0.001)$. In addition, more patients in the cetirizine group achieved complete symptom control (46\% vs. $28 \%)$. However, AE reporting was suboptimal with only a brief mention concerning lack of changes in hematochemical and urinary values, as well as report of 1 patient in the oxatomide group experiencing an allergic reaction. ${ }^{44}$

Several studies assessed treatment with sgAHs at standard dosage in pediatric patients. One double-blind randomized controlled trial (RCT) comparing treatment with desloratadine and rupatadine at standard doses for age and weight demonstrated superiority of these sgAHs against placebo in children aged 2 to 11 years. ${ }^{45}$ Similar efficacy of both treatments was observed with, $61 \%$ and $54 \%$ of patients achieving remission in the rupatadine and desloratadine groups respectively, defined as $\geq 50 \%$ decrease in the UAS-7 score. Two double-blind RCTs, including a total of 416 patients 12 years of age or older (including 21 patients aged $<18$ years), demonstrated efficacy of desloratadine $5 \mathrm{mg}$ daily against placebo. ${ }^{46,47}$ Using a 4-point pruritus scale, the 2 studies demonstrated an improvement in pruritus from baseline for desloratadine compared to placebo of $58.4 \%$ vs. $40.4 \%{ }^{46}$ and $74 \%$ vs. $48.7 \%{ }^{47}$ ( $\mathrm{p}=0.004$ and $\mathrm{p}<0.001$ respectively). A doubleblind RCT including 225 patients 12 years of age or older assessed treatment with fexofenadine $180 \mathrm{mg}$ daily and reported a decrease of 1.04 points for the fexofenadine group compared to a decrease of 0.57 point for the placebo group on a 4-point pruritus scale $(\mathrm{p}<0.001) .{ }^{48}$ The 4 mentioned RCTs assessing efficacy of sgAHs at standard doses had adequate reporting on AEs with an AE rate that was similar in both the experimental and placebo treatment groups. ${ }^{45-48}$ Two studies assessing the safety of levocetirizine hydrochloride at standard doses in infants aged 6 to 11 months and in children 2 to 11-years-old with allergic rhinitis or CSU showed similar safety profile of levocetirizine hydrochloride compared to placebo. ${ }^{49}$ An RCT assessing the safety of bilastine $10 \mathrm{mg}$ daily in 509 patients 2 to
11 years of age diagnosed with allergic rhinoconjunctivitis or CU showed no significant differences in AE profile of bilastine compared to placebo. ${ }^{50}$ However, bilastine use remains off-label in children $<12$ years of age.

\section{HI-Antihistamines at Higher Than Licensed Dosage}

Of the studies assessing updosing of sgAHs for pediatric CSU management, 2 double-blind RCTs including 605 patients 12 to 65 years of age demonstrated that rupatadine at regular dose (10 mg daily) was of comparable efficacy with rupatadine at twice the standard dose $(20 \mathrm{mg}$ daily). ${ }^{51,52}$ Another RCT including 418 patients 12 to 70 years of age compared fexofenadine against placebo at doses ranging from 20 to $240 \mathrm{mg}$ twice a day, corresponding to up to fourfold the standard dose in adolescent and adult patients. ${ }^{53}$ The improvement of urticaria symptoms with increasing fexofenadine dose up to $60 \mathrm{mg}$ twice daily followed a linear trend, at which point efficacy plateaued. Using a 4-point pruritus scale, reductions in pruritus severity from baseline were $38 \%, 54 \%, 43 \%$, and $57 \%$ in the $20,60,120$, and $240 \mathrm{mg}$ twice a day fexofenadine dose groups respectively and of $19 \%$ in the placebo group at 4-weeks. ${ }^{53}$ All 3 RCTs had adequate reporting on AEs. One study reported the rupatadine $20 \mathrm{mg}$ group had a slightly increased incidence of AE compared to standard dosage (rupatadine $10 \mathrm{mg}$ ), most commonly headache and somnolence. ${ }^{52}$ In another RCT, similar safety profiles were found for both rupatadine $10 \mathrm{mg}$ and $20 \mathrm{mg} .{ }^{51}$ The study which compared fexofenadine at different doses from 20 to $240 \mathrm{mg}$ twice a day against placebo reported similar safety profiles in all treatment groups. ${ }^{53}$

\section{Omalizumab}

Omalizumab, a humanized anti-IgE antibody, is approved by Health Canada, the FDA and other jurisdictions for the treatment of AH-resistant CSU in patients $\geq 12$-yearsold. $^{29,30,54}$ Omalizumab binds to the IgE molecule, and within 24 hours, inhibits binding to FceRI on mast cells and basophils. ${ }^{54}$ It reduces the level of free serum IgE by 96\% within 3 days and decreases FceRI expression on basophils by $73 \%$ after 7 days. ${ }^{55}$ Furthermore, additional mechanism of action of omalizumab in CSU may involve normalizing basopenia and restoring basophil activation/ histamine release (changes frequently observed in active disease). ${ }^{56}$ In adolescents and adults, it is typically administered as a single injection of 150 or $300 \mathrm{mg}$ 
subcutaneously every 4 weeks. Most commonly reported side effects include injection-site reactions, viral infections, upper respiratory tract infections, sinusitis and headaches. ${ }^{54}$ Contraindications include known hypersensitivity or anaphylaxis to any component of the formulation. ${ }^{54}$ Omalizumab use in children younger than 12 years remains off-label for CSU despite emerging data suggesting safety and efficacy in this population. ${ }^{57,58}$

Of the 16 studies reporting on treatment with omalizumab, 3 were double-blind phase 3 RCTs which included adolescent and adult patients with a total of $977 \mathrm{AH}-$ resistant CSU patients with an age range of 12 to 75 years, including 39 patients younger than 18 years of age. $^{59-61}$ In all 3 studies, subcutaneous injections were given every 4 weeks and results showed that omalizumab $300 \mathrm{mg}$ injections were effective in reducing CSU symptoms against placebo with a range of $51.9 \%$ to $66 \%$ of patients achieving UAS $\leq 6$ at week $12(\mathrm{p}<0.001) .{ }^{59-61}$ It was reported that omalizumab at a dosage of $150 \mathrm{mg}$ was sufficient to provide a significant reduction in symptoms, although less effectively than the $300 \mathrm{mg}$ dose. $^{60,61}$ Omalizumab at a dosage of $75 \mathrm{mg}$ has a similar efficacy compared to the $150 \mathrm{mg}$ group $^{61}$ in 1 study. $^{28}$ Relapse rates were described in all 3 RCTs with symptom scores reaching values similar to those in the placebo groups after treatment discontinuation, although not returning completely to baseline values. The most common AEs reported were headache and injection-site reactions. ${ }^{59-61}$

The 14 other studies assessing treatment with omalizumab were case series, case reports and our own pediatric registry including a total of $76 \mathrm{AH}-$ resistant $\mathrm{CU}$ pediatric patients (75 CSU patients and 1 otherwise non-specified CU patient) aged 4 to 17 years. ${ }^{28,55,57,58,62-71}$ The most common treatment regimen was omalizumab $300 \mathrm{mg}$ subcutaneous injections every 4 weeks. Significant improvement of symptoms was reported in 66 out of 76 patients whereas complete remission was seen in 44 patients. Clinical improvement was usually seen within 2 months. No unexpected AEs occurred.

\section{Cyclosporine}

Cyclosporine is an immunomodulating drug which inhibits the activity of calcineurin, leading to impairment of production of IL-2, IL-3, IL-4, TNF- $\alpha$ and other inflammatory cytokines and thereby, inhibiting activated T lymphocytes. ${ }^{72}$ IL-4 is involved in the generation of $\mathrm{IgE}$ and thus, cyclosporine may inhibit the IgE-mediated release of histamine from mast cell degranulation. ${ }^{73}$
Several in vitro and in vivo studies demonstrated reduction in histamine release with cyclosporine. ${ }^{74,75}$ Cyclosporine is known to have potential nephrotoxic effects and can cause hypertension. ${ }^{76}$ Its use in adult patients with various dermatologic conditions, such as psoriasis, atopic dermatitis or CSU, was demonstrated to have dose-dependent incidence of AEs with high risk of nephrotoxicity with doses of cyclosporine $>5 \mathrm{mg} / \mathrm{kg}$ / day. ${ }^{77,78}$ Absolute and/or relative contraindications to cyclosporine use include: hypersensitivity reactions, concurrent malignancy (except non-melanoma skin cancer), uncontrolled hypertension, kidney disease, uncontrolled infection, pregnancy/lactation and more. ${ }^{76}$ Its use remains off-label in treatment of CSU.

Three studies assessed treatment with cyclosporine in pediatric CSU patients including a retrospective chart review, a case series and a case report with a total of 24 AH-resistant CSU patients aged 9 to 18 years. ${ }^{79-81}$ The most common treatment regimen was cyclosporine at an initial dose of $3 \mathrm{mg} / \mathrm{kg} /$ day with slow adjustments depending on response to therapy (23 out of 24 patients) with a total duration of treatment ranging from 10 weeks to 17 months. ${ }^{79-81}$ Complete control of urticaria symptoms was reported in all 24 patients with a range of 2 days to 3 months. Additionally, it was reported that more than half of the patients experienced complete control within 2 weeks. $^{79,81}$ Time to relapse after discontinuation of the treatment was reported in 9 out of the 24 patients with a range of 1 week to 37 months. ${ }^{79,81}$ All reported relapses were responsive to repeated treatment with cyclosporine. Cyclosporine serum concentration was monitored and kept below $200 \mathrm{ng} / \mathrm{mL}$ in 23 out of 24 patients. All 3 studies described no significant AEs with no change in creatinine or blood pressure.

\section{Oral Glucocorticoids}

It is generally accepted that oral glucocorticoids are effective to reduce disease severity and/or duration of acute urticaria and CSU due to their nonspecific broad spectrum anti-inflammatory properties. ${ }^{82}$ While the international guidelines support the short-term ( $\sim 10$ days) use of systemic glucocorticoids for acute CSU exacerbations, they strongly discourage using this class of medication for long-term management of CSU due to their inevitable serious side effects and the availability of safer treatment alternatives. ${ }^{1}$ Despite the guidelines, systemic glucocorticoids remain significantly overprescribed in both adult and pediatric patients while safe and effective sgAHs are 
underutilized. ${ }^{9,83}$ One European study showed that glucocorticoids were used in up to $30 \%$ of pediatric CSU patients. ${ }^{84}$ Well-designed studies assessing the safety and the efficacity of short-term glucocorticoids in pediatric CSU patients are lacking, although their use is justified by extrapolation from adult studies and their common use in other pediatric allergic diseases. ${ }^{82,84-87}$ Long-term and repeated short-term cycles of oral/systemic glucocorticoids should be strictly avoided in adults and especially in children due to their significant adverse effects (e.g., adrenal suppression, iatrogenic Cushing's syndrome, growth impairment, etc.). ${ }^{1,88-90}$

\section{Other Treatments}

LTRAs block cysteinyl leukotrienes which are potent proinflammatory mediators and are mainly used to treat patients suffering from asthma and allergic rhinitis. ${ }^{91-93}$ The rationale for its use in CSU is supported by few in vivo and in vitro studies which have demonstrated that leukotrienes participate in inflammatory reactions of the skin including wheal formation. ${ }^{91-93}$ There is only lowquality and contradicting evidence for its efficacy as an add-on to AH therapy in adult CSU patients. ${ }^{94-96}$ Multiple studies have demonstrated reassuring safety profile of LTRAs, particularly montelukast, including in pediatric populations. ${ }^{97,98}$ The only contraindication to their use is hypersensitivity to any ingredient included in their formulation (montelukast and zafirlukast) and hepatic failure (zafirlukast). ${ }^{99,100}$ Their use remains off-label in CSU management. One double-blind RCT including $95 \mathrm{CSU}$ patients over 12 years of age compared combination treatment with cetirizine $10 \mathrm{mg}$ and zafirlukast $20 \mathrm{mg}$ twice daily to cetirizine $10 \mathrm{mg}$ monotherapy for a treatment duration of 3 weeks. ${ }^{93}$ All patients included in the study had suboptimal control with AHs. Combination therapy with zafirlukast led to a modest increase in efficacy of urticaria control, with an approximately $10 \%$ additional improvement in patient and physician-reported visual analogue scales compared to cetirizine monotherapy $(\mathrm{p}<0.05)$. Subgroup analysis demonstrated that only subjects with ASST positive results exhibited a significant improvement with combination therapy. No significant AEs were reported in either treatment groups.

Hydroxychloroquine is an antimalarial agent indicated for the treatment of malaria, systemic/discoid lupus erythematosus and rheumatoid arthritis, and which is used off-label in many other inflammatory conditions. ${ }^{101-105}$ It is thought to exert immunomodulatory properties by modulating antigen presentation, inhibiting DNA synthesis and normalizing interleukin profile. ${ }^{106}$ While hydroxychloroquine is generally considered very safe, possible side effects include ocular, neuromuscular, liver and hematologic toxicities. ${ }^{107,108}$ To decrease the risk of permanent retinal damage, the American Academy of Ophthalmology recommends limiting the daily dosage to a maximum of $5 \mathrm{mg} / \mathrm{kg}$ (real weight) with baseline fundus examination, followed by annual follow up examination after 1-5 years of use depending on risk factors. ${ }^{109}$ While 1 small single-blind RCT including 48 adult patients with AH-resistant CSU demonstrated a superiority of hydroxychloroquine $400 \mathrm{mg}$ daily over placebo in improving quality of life and reducing urticaria severity score at 12 weeks, ${ }^{110}$ data in pediatric CSU is largely lacking. So far, only 1 case report was identified, describing successful treatment of a 9-month-old infant with AH-resistant disease with hydroxychloroquine doses up to $6 \mathrm{mg} / \mathrm{kg} /$ day. ${ }^{111}$ Additional studies are warranted prior to recommending hydroxychloroquine in AH-resistant CSU in children.

A prospective case-control study including 58 patients (14 years of age or older) assessing vitamin D supplementation (at $300000 \mathrm{IU} / \mathrm{month}^{112}$ and a case report of a 14-year-old patient who was treated with vitamin D (at 50,000 IU weekly for five doses then $2000 \mathrm{IU}$ daily $)^{113}$ demonstrated that vitamin $\mathrm{D}$ supplementation may be beneficial in the reduction of CSU symptoms in patients with demonstrated vitamin D deficiency. However, given that the case-control study was not randomized there is a potential for confounding and findings are thus not conclusive. A comparative study including 24 patients $>14$ years of age compared the efficacy of 2 phototherapy regimens (psoralen and ultraviolet A [PUVA] vs. narrowband ultraviolet B [NB UVB]). Results showed similar reduction in CSU symptoms with no significant difference in outcome in both treatment groups. ${ }^{114} \mathrm{~A}$ systematic review which included multiple small studies, including 2 studies on pediatric patients, demonstrated that allergen-specific immunotherapy may be beneficial in the treatment of CSU in patients with IgEmediated allergy. ${ }^{115}$ Finally, while children were excluded from recently published RCT employing ligelizumab (a newer generation anti-IgE monoclonal antibody) for controlling moderate to severe AH-resistant CSU, 4 active clinical trials including adolescent patients are ongoing. ${ }^{116}$ 


\section{Conclusion}

Our review exemplifies that the medical literature strongly supports extension of EAACI/GA ${ }^{2} \mathrm{LEN} / \mathrm{EDF} / \mathrm{WAO}$ treatment guidelines to the pediatric population (Table 2). However, we also highlight several knowledge gaps regarding treatment options for pediatric patients under 12 years of age with refractory CSU, such as increasing doses of AHs, or initiating omalizumab. Moreover, there is scarce evidence regarding the efficacy and safety profiles of cyclosporine and LTRAs in pediatric patients of all ages.

The use of sgAHs as a first-line treatment for CSU in children has been explored and validated by several studies, including large and well-designed RCTs, which have demonstrated both efficacy in symptoms reduction and control, as well as an excellent safety profile at standard dosing. ${ }^{44-53}$ There are few studies which compared and contrasted the efficacy and safety of different sgAHs; thus, there is not one specific sgAH that is preferably recommended. ${ }^{1,20,21}$ The response to $\mathrm{AHs}$ in children with CSU has not yet been extensively studied, but our own data recently indicated that up to $90 \%$ of children can be adequately and safely controlled with sgAH at licensed or increased dosage. ${ }^{28}$ While fgAHs remain commonly used in pediatric CU (CSU and CIndU), there is a lack of evidence to support their efficacy/safety in the pediatric population and because of their potential to cross brainblood-barrier, clinicians should refrain from using them unless sgAHs are unavailable.

In cases of disease refractory to AHs, omalizumab has been shown to effectively and safely reduce symptoms in children aged 12 years and older through large RCTs. ${ }^{59-61}$ Although these are promising results, the small number of adolescent patients included in the studies (combined total of 39 patients) is an inherent limitation. Omalizumab's efficacy and safety in children with CSU under 12 years of age has been reported only in case series and case reports. ${ }^{55,57,58,62,65-71}$ Hence, larger studies are required in order to confirm the safety and efficacy of omalizumab in children younger than 12 years.

Studies assessing treatment with cyclosporine in children aged 9 years and older and adolescents with CSU included small retrospective studies and case reports with low levels of evidence. ${ }^{79-81}$ In these studies, cyclosporine at an initial dose of 3 to $4 \mathrm{mg} / \mathrm{kg} / \mathrm{day}$, with slow adjustments depending on patient response, was reported to be safe and effective in reducing CSU symptoms and achieving remission in the vast majority of patients. ${ }^{77,78} 117$ Additionally, the need for regular laboratory monitoring of cyclosporine-related complications can represent a significant limitation to its use in children. ${ }^{118,119}$ While no RCTs specifically assessed efficacy of neither cyclosporine nor omalizumab in children, because omalizumab has been used for asthma for many years in children $>6$ years of age, ${ }^{120}$ we believe that cyclosporine use in children should be considered only when management with omalizumab fails. There is insufficient evidence for other treatment modalities including LTRAs.

\section{Author Contributions}

All authors made a significant contribution to the work reported, whether that is in the conception, study design, execution, acquisition of data, analysis and interpretation, or in all these areas; took part in drafting, revising or critically reviewing the article; gave final approval of the version to be published; have agreed on the journal to which the article has been submitted; and agree to be accountable for all aspects of the work.

\section{Funding}

This work received no specific grant from any funding agency in the public, commercial, or not-for-profit sectors.

\section{Disclosure}

Dr. Ben-Shoshan is a consultant, speaker and investigator for Novartis and participated in a clinical trial related to the use of ligelizumab. Dr. Elena Netchiporouk has received investigator-initiated project grants from Eli Lilly, LEO Pharma, Beiersdorf, AbbVie and has served as a consultant/advisory for Leo pharma, Sanofi Genzyme, Eli Lilly, Novartis, Bausch, Janssen, Galderma (advisory board only). She has served as a speaker for Bausch, Janssen, Novartis, Sun Pharma and LEO Pharma. The authors report no other potential conflicts of interest for this work.

\section{References}

1. Zuberbier T, Aberer W, Asero R, et al. The EAACI/GA 2 LEN/EDF/ WAO guideline for the definition, classification, diagnosis and management of urticaria. Allergy. 2018;73(7):1393-1414. doi:10.1111/ all.13397

2. Saini S, Shams M, Bernstein JA, Maurer M. Urticaria and angioedema across the ages. J Allergy Clin Immunol Pract. 2020;8(6):1866-1874. doi:10.1016/j.jaip.2020.03.030 
3. Fricke J, Ávila G, Keller T, et al. Prevalence of chronic urticaria in children and adults across the globe: systematic review with meta-analysis. Allergy. 2020;75(2):423-432. doi:10.1111/all.14 037

4. Goldstein S, Gabriel S, Kianifard F, Ortiz B, Skoner DP. Clinical features of adolescents with chronic idiopathic or spontaneous urticaria: review of omalizumab clinical trials. Ann Allergy Asthma Immunol. 2017;118(4):500-504. doi:10.1016/j.anai.2017. 02.003

5. Curto-Barredo L, Pujol RM, Roura-Vives G, Gimenez-Arnau AM. Chronic urticaria phenotypes: clinical differences regarding triggers, activity, prognosis and therapeutic response. Eur J Dermatol. 2019;29(6):627-635. doi:10.1684/ejd.2019.3674

6. Netchiporouk E, Sasseville D, Moreau L, Habel Y, Rahme E, Ben-Shoshan M. Evaluating comorbidities, natural history, and predictors of early resolution in a cohort of children with chronic urticaria. JAMA Dermatol. 2017;153(12):1236-1242. doi:10.10 01/jamadermatol.2017.3182

7. Fernando S, Broadfoot A. Chronic urticaria-assessment and treatment. Aust Fam Physician. 2010;39(3):135-138.

8. Cornillier H, Giraudeau B, Munck S, et al. Chronic spontaneous urticaria in children - a systematic review on interventions and comorbidities. Pediatr Allergy Immunol. 2018;29(3):303-310. doi:10.1111/pai.12870

9. Williams PV. Pharmacologic management of chronic urticaria in pediatric patients: the gap between guidelines and practice. Paediatr Drugs. 2020;22(1):21-28. doi:10.1007/s40272-019-00 365-3

10. Sahiner UM, Civelek E, Tuncer A, et al. Chronic urticaria: etiology and natural course in children. Int Arch Allergy Immunol. 2011;156(2):224-230. doi:10.1159/000322349

11. Caffarelli C, Cuomo B, Cardinale F, et al. Aetiological factors associated with chronic urticaria in children: a systematic review. Acta Derm Venereol. 2013;93(3):268-272. doi:10.2340/000155 55-1511

12. Bracken SJ, Abraham S, MacLeod AS. Autoimmune theories of chronic spontaneous urticaria. Front Immunol. 2019;10:627. doi:10.3389/fimmu.2019.00627

13. Altman K, Chang C. Pathogenic intracellular and autoimmune mechanisms in urticaria and angioedema. Clin Rev Allergy Immunol. 2013;45(1):47-62. doi:10.1007/s12016-012-8326-y

14. Du Toit G, Prescott R, Lawrence P, et al. Autoantibodies to the high-affinity $\mathrm{IgE}$ receptor in children with chronic urticaria. Ann Allergy Asthma Immunol. 2006;96(2):341-344. doi:10.1016/ S1081-1206(10)61245-8

15. Kolkhir P, Metz M, Altrichter S, Maurer M. Comorbidity of chronic spontaneous urticaria and autoimmune thyroid diseases: A systematic review. Allergy. 2017;72(10):1440-1460. doi:10.11 11/all.13182

16. Schmetzer O, Lakin E, Topal FA, et al. IL-24 is a common and specific autoantigen of IgE in patients with chronic spontaneous urticaria. J Allergy Clin Immunol. 2018;142(3):876-882. doi:10. 1016/j.jaci.2017.10.035

17. Kolkhir P, Church MK, Weller K, Metz M, Schmetzer O, Maurer M. Autoimmune chronic spontaneous urticaria: what we know and what we do not know. J Allergy Clin Immunol. 2017;139(6):1772-1781 e1771. doi:10.1016/j.jaci.2016.08.050

18. Asero R, Marzano AV, Ferrucci S, Lorini M, Carbonelli V, Cugno M. Co-occurrence of IgE and IgG autoantibodies in patients with chronic spontaneous urticaria. Clin Exp Immunol. 2020;200(3):242-249. doi:10.1111/cei.13428

19. Altrichter S, Zampeli V, Ellrich A, Zhang K, Church MK, Maurer M. IgM and IgA in addition to IgG autoantibodies against FceRI $\alpha$ are frequent and associated with disease markers of chronic spontaneous urticaria. Allergy. 2020;75(12):3208-3215. doi:10.1111/all.14412
20. Caffarelli C, Paravati F, El Hachem M, et al. Management of chronic urticaria in children: a clinical guideline. Ital J Pediatr. 2019;45(1):101.

21. Bernstein JA, Lang DM, Khan DA, et al. The diagnosis and management of acute and chronic urticaria: 2014 update. J Allergy Clin Immunol. 2014;133(5):1270-1277. doi:10.1016/j.jaci.2014.02.036

22. Hawro T, Ohanyan T, Schoepke N, et al. The urticaria activity score-validity, reliability, and responsiveness. J Allergy Clin Immunol Pract. 2018;6(4):1185-1190.e1181. doi:10.1016/j.jaip. 2017.10.001

23. Weller K, Groffik A, Church MK, et al. Development and validation of the urticaria control test: a patient-reported outcome instrument for assessing urticaria control. J Allergy Clin Immunol. 2014;133(5):1365-1372, 1372.e1361-1366. doi:10.10 16/j.jaci.2013.12.1076

24. Stull D, McBride D, Tian H, et al. Analysis of disease activity categories in chronic spontaneous/idiopathic urticaria. $\mathrm{Br}$ J Dermatol. 2017;177(4):1093-1101. doi:10.1111/bjd.15454

25. Tondury B, Muehleisen B, Ballmer-Weber BK, et al. The pictorial representation of illness and self measure (PRISM) instrument reveals a high burden of suffering in patients with chronic urticaria. J Investig Allergol Clin Immunol. 2011;21(2):93-100.

26. Ferrer M. Epidemiology, healthcare, resources, use and clinical features of different types of urticaria. Alergologica 2005. J Investig Allergol Clin Immunol. 2009;19(Suppl 2):21-26.

27. Hergüner S, Kiliç G, Karakoç S, Tamay Z, Tüzün U, Güler N. Levels of depression, anxiety and behavioural problems and frequency of psychiatric disorders in children with chronic idiopathic urticaria. $\mathrm{Br} J$ Dermatol. 2011;164(6):1342-1347. doi:10.1111/j.1365-2133.2010.10138.x

28. Gabrielli S, Le M, Netchiporouk E, et al. Chronic urticaria in children can be controlled effectively with updosing second-generation antihistamines. J Am Acad Dermatol. 2020;82 (6):1535-1537. doi:10.1016/j.jaad.2020.02.041

29. Kolkhir P, Altrichter S, Munoz M, Hawro T, Maurer M. New treatments for chronic urticaria. Ann Allergy Asthma Immunol. 2020;124(1):2-12. doi:10.1016/j.anai.2019.08.014

30. Chipps BE, Lanier B, Milgrom H, et al. Omalizumab in children with uncontrolled allergic asthma: review of clinical trial and real-world experience. J Allergy Clin Immunol. 2017;139 (5):1431-1444. doi:10.1016/j.jaci.2017.03.002

31. Church MK, Maurer M, Simons FE, et al. Risk of first-generation H(1)-antihistamines: a GA(2)LEN position paper. Allergy. 2010;65(4):459-466. doi:10.1111/j.1398-9995.2009.02325.x

32. Simons FE, Simons KJ. Histamine and H1-antihistamines: celebrating a century of progress. J Allergy Clin Immunol. 2011;128 (6):1139-1150.e1134. doi:10.1016/j.jaci.2011.09.005

33. Kalpaklioglu F, Baccioglu A. Efficacy and safety of H1-antihistamines: an update. Antiinflamm Antiallergy Agents Med Chem. 2012;11(3):230-237. doi:10.2174/1871523011202030230

34. Simons FE. H1-antihistamines in children. Clin Allergy Immunol. 2002;17:437-464.

35. Fitzsimons R, van der Poel LA, Thornhill W, Du Toit G, Shah N, Brough HA. Antihistamine use in children. Arch Dis Child Educ Pract Ed. 2015;100(3):122-131. doi:10.1136/archdischild-2013-304446

36. Wood RA, Khan DA, Lang DM, et al. American academy of allergy, asthma and immunology response to the EAACI/GA(2) LEN/EDF/WAO guideline for the definition, classification, diagnosis, and management of Urticaria 2017 revision. Allergy. 2019;74(2):411-413. doi:10.1111/all.13636

37. Bolognia J, Schaffer JV, Cerroni L. Dermatology. 4th rev. ed. Philadelphia: Elsevier; 2018. 2880p.

38. Palmer RB, Reynolds KM, Banner W, et al. Adverse events associated with diphenhydramine in children, 2008-2015. Clin Toxicol (Phila). 2020;58(2):99-106. doi:10.1080/ 15563650.2019 .1609683 
39. De Bruyne P, Christiaens T, Boussery K, Mehuys E, Van Winckel M. Are antihistamines effective in children? A review of the evidence. Arch Dis Child. 2017;102(1):56-60. doi:10.1136/ archdischild-2015-310416

40. Simons FE, Simons KJ. H1 antihistamines: current status and future directions. World Allergy Organ J. 2008;1(9):145-155. doi:10.1097/WOX.0b013e318186fb3a

41. Yanai K, Yoshikawa T, Yanai A, et al. The clinical pharmacology of non-sedating antihistamines. Pharmacol Ther. 2017;17 8:148-156. doi:10.1016/j.pharmthera.2017.04.004

42. Bosma R, van den Bor J, Vischer HF, Labeaga L, Leurs R. The long duration of action of the second generation antihistamine bilastine coincides with its long residence time at the histamine $\mathrm{H}$ (1) receptor. Eur J Pharmacol. 2018;838:107-111. doi:10.1016/j. ejphar.2018.09.011

43. Wolverton SE. Comprehensive Dermatologic Drug Therapy: Expert Consult - Online and Print. Elsevier Health Sciences; 2012.

44. La Rosa M, Leonardi S, Marchese G, et al. Double-blind multicenter study on the efficacy and tolerability of cetirizine compared with oxatomide in chronic idiopathic urticaria in preschool children. Ann Allergy Asthma Immunol. 2001;87(1):48-53. doi:10.1016/S1081-1206(10)62322-8

45. Potter P, Mitha E, Barkai L, et al. Rupatadine is effective in the treatment of chronic spontaneous urticaria in children aged 2-11 years. Pediatr Allergy Immunol. 2016;27(1):55-61. doi:10.1111/ pai. 12460

46. Monroe E, Finn A, Patel P, Guerrero R, Ratner P, Bernstein D. Efficacy and safety of desloratadine $5 \mathrm{mg}$ once daily in the treatment of chronic idiopathic urticaria: a double-blind, randomized, placebo-controlled trial. J Am Acad Dermatol. 2003;48 (4):535-541. doi:10.1067/mjd.2003.143

47. Ring J, Hein R, Gauger A, Bronsky E, Miller B. Once-daily desloratadine improves the signs and symptoms of chronic idiopathic urticaria: a randomized, double-blind, placebo-controlled study. Int $J$ Dermatol. 2001;40(1):72-76. doi:10.1046/j.13654362.2001.00186.x

48. Kaplan AP, Spector SL, Meeves S, Liao Y, Varghese ST, Georges G. Once-daily fexofenadine treatment for chronic idiopathic urticaria: a multicenter, randomized, double-blind, placebo-controlled study. Ann Allergy Asthma Immunol. 2005;94 (6):662-669. doi:10.1016/S1081-1206(10)61325-7

49. Hampel F, Ratner P, Haeusler JM. Safety and tolerability of levocetirizine dihydrochloride in infants and children with allergic rhinitis or chronic urticaria. Allergy Asthma Proc. 2010;31 (4):290-295. doi:10.2500/aap.2010.31.3349

50. Novak Z, Yanez A, Kiss I, et al. Safety and tolerability of bilastine $10 \mathrm{mg}$ administered for 12 weeks in children with allergic diseases. Pediatr Allergy Immunol. 2016;27(5):493-498. doi:10. 1111/pai.12555

51. Hide M, Suzuki T, Tanaka A, Aoki H. Efficacy and safety of rupatadine in Japanese adult and adolescent patients with chronic spontaneous urticaria: A double-blind, randomized, multicenter, placebo-controlled clinical trial. Allergol Int. 2019;68(1):59-67. doi:10.1016/j.alit.2018.06.002

52. Gimenez-Arnau A, Pujol RM, Ianosi S, et al. Rupatadine in the treatment of chronic idiopathic urticaria: a double-blind, randomized, placebo-controlled multicentre study. Allergy. 2007;62 (5):539-546. doi:10.1111/j.1398-9995.2007.01330.x

53. Nelson HS, Reynolds R, Mason J. Fexofenadine $\mathrm{HCl}$ is safe and effective for treatment of chronic idiopathic urticaria. Ann Allergy Asthma Immunol. 2000;84(5):517-522. doi:10.1016/S10811206(10)62515-X

54. Inc. NPC. Product Monograph - XOLAIR ${ }^{\circledR}$ (Omalizumab); 2015. Available from: https:/www.novartis.ca/sites/www.novartis.ca/ files/xolair_scrip_e.pdf. Accessed March 22, 2020.
55. Netchiporouk E, Nguyen $\mathrm{CH}$, Thuraisingham $\mathrm{T}$, Jafarian $\mathrm{F}$, Maurer M, Ben-Shoshan M. Management of pediatric chronic spontaneous and physical urticaria patients with omalizumab: case series. Pediatr Allergy Immunol. 2015;26(6):585-588. doi:10.1111/pai.12407

56. Poddighe D, Vangelista L. Effects of omalizumab on basophils: potential biomarkers in asthma and chronic spontaneous urticaria. Cell Immunol. 2020;358:104215. doi:10.1016/j.cellimm.2020.104215

57. Ari A, Levy Y, Segal N, et al. Efficacy of omalizumab treatment for pediatric chronic spontaneous urticaria: A multi-center retrospective case series. Pediatr Dermatol. 2020;37(6):1051-1054. doi:10.1111/pde. 14360

58. Staubach P, Peveling-Oberhag A, Lang BM, Zimmer S, Sohn A, Mann C. Severe chronic spontaneous urticaria in children - treatment options according to the guidelines and beyond - a 10 years review. J Dermatolog Treat. 2020;1-4. doi:10.1080/095466 34.2020.1782326

59. Kaplan A, Ledford D, Ashby M, et al. Omalizumab in patients with symptomatic chronic idiopathic/spontaneous urticaria despite standard combination therapy. J Allergy Clin Immunol. 2013;132(1):101-109. doi:10.1016/j.jaci.2013.05.013

60. Maurer M, Rosén K, Hsieh HJ, et al. Omalizumab for the treatment of chronic idiopathic or spontaneous urticaria. $N$ Engl $J$ Med. 2013;368(10):924-935. doi:10.1056/NEJMoa1215372

61. Saini SS, Bindslev-Jensen C, Maurer M, et al. Efficacy and safety of omalizumab in patients with chronic idiopathic/spontaneous urticaria who remain symptomatic on $\mathrm{H} 1$ antihistamines: a randomized, placebo-controlled study. $J$ Invest Dermatol. 2015;135(1):67-75. doi:10.1038/jid.2014.306

62. Asero R, Casalone R, Iemoli E. Extraordinary response to omalizumab in a child with severe chronic urticaria. Eur Ann Allergy Clin Immunol. 2014;46(1):41-42.

63. Parisi GF, Papale M, Tardino LG, et al. Omalizumab treatment in a 12 year-old girl with chronic spontaneous urticaria. J Dermatolog Treat. 2018;29(sup4):10-11. doi:10.1080/0954 6634.2018.1551609

64. Porcaro F, Di Marco A, Cutrera R. Omalizumab in patient with aspirin exacerbated respiratory disease and chronic idiopathic urticaria. Pediatr Pulmonol. 2017;52(5):E26-E28. doi:10.1002/ppul.23615

65. Uysal P, Erge D. Effective treatment of different H1-antihistamine-refractory chronic urticaria phenotypes with omalizumab. Turk Pediatri Ars. 2018;53(4):250-254. doi:10. 5152/TurkPediatriArs.2016.4042

66. Passanisi S, Arasi S, Caminiti L, Crisafulli G, Salzano G, Pajno GB. Omalizumab in children and adolescents with chronic spontaneous urticaria: case series and review of the literature. Dermatol Ther. 2020;33(4):e13489. doi:10.1111/dth.13489

67. Al-Shaikhly T, Rosenthal JA, Ayars AG, Petroni DH. Omalizumab for chronic urticaria in children younger than 12 years. Ann Allergy Asthma Immunol. 2019;123(2):208-210 e202. doi:10.1016/j.anai.2019.05.003

68. Sirufo MM, Ginaldi L, De Martinis M. Successful treatment with omalizumab in a child with asthma and urticaria: a clinical case report. Front Pediatr. 2019;7:213. doi:10.3389/fped.2019.00213

69. Jesenak M, Ciljakova M, Janickova M, Banovcin P. Omalizumab in an 8-year-old boy with diabetes mellitus and refractory chronic spontaneous urticaria. J Investig Allergol Clin Immunol. 2019;29 (2):144-146. doi:10.18176/jiaci.0351

70. Ossorio-García L, Jiménez-Gallo D, Albarrán-Planelles C, Arjona-Aguilera C, Linares-Barrios M. Chronic spontaneous urticaria in an 8-year-old girl treated with omalizumab. Clin Exp Dermatol. 2016;41(8):929-930. doi:10.1111/ced.12922

71. Leonardi L, Uva A, Duse M. Chronic urticaria in a child affected by atopic dermatitis: effective treatment with omalizumab. J Dermatolog Treat. 2018;29(sup3):17-19. doi:10.1080/09546 634.2018 .1543844 
72. Matsuda S, Koyasu S. Mechanisms of action of cyclosporine. Immunopharmacology. 2000;47(2-3):119-125. doi:10.1016/ S0162-3109(00)00192-2

73. Harrison CA, Bastan R, Peirce MJ, Munday MR, Peachell PT. Role of calcineurin in the regulation of human lung mast cell and basophil function by cyclosporine and FK506. Br J Pharmacol. 2007;150(4):509-518. doi:10.1038/sj.bjp.0707002

74. Grattan CEH, O'Donnell BF, Francis DM, et al. Randomized double-blind study of cyclosporin in chronic 'idiopathic' urticaria. Br J Dermatol. 2000;143(2):365-372. doi:10.1046/j.13652133.2000.03664.x

75. Marsland AM, Soundararajan S, Joseph K, Kaplan AP. Effects of calcineurin inhibitors on an in vitro assay for chronic urticaria. Clin Exp Allergy. 2005;35(5):554-559.

76. Inc. NPC. Product Monograph - Neoral ${ }^{\circledR}$ and Sandimmune ${ }^{\circledR}$ (Cyclosporine); 2015. Available from: http://www.ask.novarti spharma.ca/download.htm?res=neoral_scrip_e.pdf\&resTitleId= 691. Accessed August 22, 2020.

77. Kulthanan K, Chaweekulrat P, Komoltri C, et al. Cyclosporine for chronic spontaneous urticaria: a meta-analysis and systematic review. J Allergy Clin Immunol Pract. 2018;6(2):586-599. doi:10.1016/j.jaip.2017.07.017

78. Ryan C, Amor KT, Menter A. The use of cyclosporine in dermatology: part II. J Am Acad Dermatol. 2010;63(6):949-972; quiz 973-944. doi:10.1016/j.jaad.2010.02.062

79. Doshi DR, Weinberger MM. Experience with cyclosporine in children with chronic idiopathic urticaria. Pediatr Dermatol. 2009;26(4):409-413. doi:10.1111/j.1525-1470.2009.00869.x

80. Giuliodori K, Ganzetti G, Campanati A, Simonetti O, Marconi B, Offidani A. A non-responsive chronic autoimmune urticaria in a 12-year-old autistic girl treated with cyclosporin. J Eur Acad Dermatol Venereol. 2009;23(5):619-620. doi:10.1111/j.14683083.2008.02987.x

81. Neverman L, Weinberger M. Treatment of chronic urticaria in children with antihistamines and cyclosporine. J Allergy Clin Immunol Pract. 2014;2(4):434 438. doi:10.1016/j.jaip.2014.04.011

82. Asero R, Tedeschi A. Usefulness of a short course of oral prednisone in antihistamine-resistant chronic urticaria: a retrospective analysis. J Investig Allergol Clin Immunol. 2010;20(5):386-390.

83. Ledford D, Broder MS, Antonova E, Omachi TA, Chang E, Luskin A. Corticosteroid-related toxicity in patients with chronic idiopathic urticariachronic spontaneous urticaria. Allergy Asthma Proc. 2016;37(6):458-465. doi:10.2500/aap.2016.37.3999

84. Balp MM, Weller K, Carboni V, et al. Prevalence and clinical characteristics of chronic spontaneous urticaria in pediatric patients. Pediatr Allergy Immunol. 2018;29(6):630-636. doi:10. 1111/pai.12910

85. Poddighe D, Brambilla I, Licari A, Marseglia GL. Paediatric severe chronic spontaneous urticaria: successful management through conventional drug therapy. BMJ Case Rep. 2019;12(8): e230925. doi:10.1136/bcr-2019-230925

86. Normansell R, Kew KM, Mansour G. Different oral corticosteroid regimens for acute asthma. Cochrane Database Syst Rev. 2016;5:Cd011801.

87. De Filippo M, Clark E, Fillard A, Diaferio L, Caimmi D. Oral corticosteroids and asthma in children: practical considerations. Pediatr Allergy Immunol. 2020;31(Suppl 24):43-45. doi:10.1111/ pai. 13151

88. Donatti TL, Koch VH, Takayama L, Pereira RM. Effects of glucocorticoids on growth and bone mineralization. J Pediatr (Rio J). 2011;87(1):4-12. doi:10.1590/S0021-75572011000100 002

89. McDonough AK, Curtis JR, Saag KG. The epidemiology of glucocorticoid-associated adverse events. Curr Opin Rheumatol. 2008;20(2):131-137. doi:10.1097/BOR.0b013e $3282 \mathrm{f} 51031$
90. Gabrielli S, Le M, Netchiporouk E, et al. Reply to "Comment on: 'Children with chronic urticaria can be effectively controlled with updosing second-generation antihistamines"”. $J$ Am Acad Dermatol. 2020;83(5):e365-e366. doi:10.1016/j.jaad.2020.06.997

91. Wedi B, Novacovic V, Koerner M, Kapp A. Chronic urticaria serum induces histamine release, leukotriene production, and basophil CD63 surface expression-inhibitory effects of antiinflammatory drugs. $J$ Allergy Clin Immunol. 2000;105 (3):552-560. doi:10.1067/mai.2000.104939

92. Bisgaard H. Vascular effects of leukotriene D4 in human skin. J Invest Dermatol. 1987;88(2):109-114. doi:10.1111/1523-1747. ep12525225

93. Bagenstose SE, Levin L, Bernstein JA. The addition of zafirlukast to cetirizine improves the treatment of chronic urticaria in patients with positive autologous serum skin test results. J Allergy Clin Immunol. 2004;113(1):134-140. doi:10.1016/j.jaci.2003.10.002

94. Di Lorenzo G, Pacor ML, Mansueto P, et al. Is there a role for antileukotrienes in urticaria? Clin Exp Dermatol. 2006;31 (3):327-334. doi:10.1111/j.1365-2230.2006.02127.x

95. McBayne TO, Siddall OM. Montelukast treatment of urticaria. Ann Pharmacother. 2006;40(5):939-942. doi:10.1345/aph.1G006

96. de Silva NL, Damayanthi H, Rajapakse AC, Rodrigo C, Rajapakse S. Leukotriene receptor antagonists for chronic urticaria: a systematic review. Allergy Asthma Clin Immunol. 2014;10 (1):24. doi:10.1186/1710-1492-10-24

97. Bisgaard H, Skoner D, Boza ML, et al. Safety and tolerability of montelukast in placebo-controlled pediatric studies and their open-label extensions. Pediatr Pulmonol. 2009;44(6):568-579. doi:10.1002/ppul.21018

98. Hon KL, Leung TF, Leung AK. Clinical effectiveness and safety of montelukast in asthma. What are the conclusions from clinical trials and meta-analyses? Drug Des Devel Ther. 2014;8:839-850. doi:10.2147/DDDT.S39100

99. Accolate [package insert]. Wilmington, DE: AstraZeneca; November 2013

100. Singulair (montelukast) [prescribing information]. Whitehouse Station, NJ: Merck and Co, Inc; April 2020.

101. Fanouriakis A, Kostopoulou M, Alunno A, et al. 2019 update of the EULAR recommendations for the management of systemic lupus erythematosus. Ann Rheum Dis. 2019;78(6):736-745. doi:10.1136/annrheumdis-2019-215089

102. Fiehn C, Ness T, Weseloh C, et al. Safety management in treatment with antimalarials in rheumatology. Interdisciplinary recommendations on the basis of a systematic literature review. Z Rheumatol. 2020. doi:10.1007/s00393-020-00785-4

103. Ang GC, Werth VP. Combination antimalarials in the treatment of cutaneous dermatomyositis: a retrospective study. Arch Dermatol. 2005;141(7):855-859. doi:10.1001/archderm.141.7.855

104. Gottenberg JE, Ravaud P, Puéchal X, et al. Effects of hydroxychloroquine on symptomatic improvement in primary Sjögren syndrome: the JOQUER randomized clinical trial. JAMA. 2014;312(3):249-258. doi:10.1001/jama.2014.7682

105. Fernandez AP. Updated recommendations on the use of hydroxychloroquine in dermatologic practice. $J$ Am Acad Dermatol. 2017;76(6):1176-1182. doi:10.1016/j.jaad.2017.01.012

106. Schrezenmeier E, Dörner T. Mechanisms of action of hydroxychloroquine and chloroquine: implications for rheumatology. Nat Rev Rheumatol. 2020;16(3):155-166. doi:10.1038/s41584-0200372-x

107. Costedoat-Chalumeau N, Dunogué B, Leroux G, et al. A critical review of the effects of hydroxychloroquine and chloroquine on the eye. Clin Rev Allergy Immunol. 2015;49(3):317-326. doi:10. 1007/s12016-015-8469-8

108. Lebin JA, LeSaint KT. Brief review of chloroquine and hydroxychloroquine toxicity and management. West J Emerg Med. 2020;21(4):760-763. doi:10.5811/westjem.2020.5.47810 
109. Marmor MF, Kellner U, Lai TY, Melles RB, Mieler WF. Recommendations on screening for chloroquine and hydroxychloroquine retinopathy (2016 revision). Ophthalmology. 2016;123(6):1386-1394. doi:10.1016/j.ophtha.2016.01.058

110. Boonpiyathad T, Sangasapaviliya A. Hydroxychloroquine in the treatment of anti-histamine refractory chronic spontaneous urticaria, randomized single-blinded placebo-controlled trial and an open label comparison study. Eur Ann Allergy Clin Immunol. 2017;49(5):220-224. doi:10.23822/EurAnnACI.1764-1489.11

111. Iweala OI, Copenhaver $\mathrm{C}$, Wu EY, Moran TP. Hydroxychloroquine as a steroid-sparing agent in an infant with chronic urticaria. Ann Allergy Asthma Immunol. 2018;120 (1):102-104. doi:10.1016/j.anai.2017.10.011

112. Oguz Topal I, Kocaturk E, Gungor S, Durmuscan M, Sucu V, Yildirmak S. Does replacement of vitamin D reduce the symptom scores and improve quality of life in patients with chronic urticaria? J Dermatolog Treat. 2016;27(2):163-166. doi:10.31 09/09546634.2015.1079297

113. Yuan I, Katari P, Shaker M. Vitamin D treatment for chronic urticaria: a case report. J Med Case Rep. 2019;13(1):193. doi:10.1186/s13256-019-2121-9

114. Khafagy NH, Salem SA, Ghaly EG. Comparative study of systemic psoralen and ultraviolet $\mathrm{A}$ and narrowband ultraviolet $\mathrm{B}$ in treatment of chronic urticaria. Photodermatol Photoimmunol Photomed. 2013;29(1):12-17. doi:10.1111/phpp.12008
115. Shi CR, Li YP, Luo YJ, et al. IgE-mediated allergy: a rare cause of chronic spontaneous urticarial with allergen-specific immunotherapy as treatment option - a systematic review with meta-analysis from China. J Eur Acad Dermatol Venereol. 2012;26(5):533-544. doi:10.1111/j.1468-3083.2011.04302.x

116. Maurer M, Giménez-Arnau AM, Sussman G, et al. Ligelizumab for chronic spontaneous urticaria. N Engl J Med. 2019;381 (14):1321-1332. doi:10.1056/NEJMoa1900408

117. Boubouka CD, Charissi C, Kouimintzis D, Kalogeromitros D, Stavropoulos PG, Katsarou A. Treatment of autoimmune urticaria with low-dose cyclosporin A: a one-year follow-up. Acta Derm Venereol. 2011;91(1):50-54. doi:10.2340/00015555-0939

118. Blake SC, Murrell DF. Monitoring trough levels in cyclosporine for atopic dermatitis: A systematic review. Pediatr Dermatol. 2019;36(6):843-853. doi:10.1111/pde.13999

119. Yee J, Orchard D. Monitoring recommendations for oral azathioprine, methotrexate and cyclosporin in a paediatric dermatology clinic and literature review. Australas J Dermatol. 2018;59 (1):31-40. doi:10.1111/ajd.12526

120. Xolair (Omalizumab) [package insert]. Dorval, QC: Novartis Pharmaceuticals Canada Inc.; 2015.

\section{Publish your work in this journal}

The Journal of Asthma and Allergy is an international, peer-reviewed open-access journal publishing original research, reports, editorials and commentaries on the following topics: Asthma; Pulmonary physiology; Asthma related clinical health; Clinical immunology and the immunological basis of disease; Pharmacological interventions and new therapies. The manuscript management system is completely online and includes a very quick and fair peer-review system, which is all easy to use. Visit http://www.dovepress.com/testimonials.php to read real quotes from published authors. 